University of South Florida

DIGITAL COMMONS

Digital Commons @ University of

@ UNIVERSITY OF SOUTH FLORIDA

South Florida

QMaSC: A Handbook for Directors of

Quantitative and Mathematics Support Centers

USF Libraries

$1-1-2016$

\title{
09. Outreach and Promotion
}

Laurie Wern Overmann

Southeast Missouri State University

Follow this and additional works at: https://digitalcommons.usf.edu/qmasc_handbook

\section{Recommended Citation}

Laurie Wern Overmann (2016), "Outreach and Promotion", http://dx.doi.org/10.5038/ 9780977674435.ch9 in G. Coulombe, M. O'Neill, M. Schuckers (Eds.) A Handbook for Directors of Quantitative and Mathematical Support Centers, Neck Quill Press, http://scholarcommons.usf.edu/qmasc_handbook.

This Community Interactions is brought to you for free and open access by the USF Libraries at Digital Commons @ University of South Florida. It has been accepted for inclusion in QMaSC: A Handbook for Directors of Quantitative and Mathematics Support Centers by an authorized administrator of Digital Commons @ University of South Florida. For more information, please contact digitalcommons@usf.edu. 


\title{
Outreach and Promotion
}

\author{
(C) Laurie Wern Overmann, \\ Southeast Missouri State University
}

口]

\section{Introduction}

A Quantitative Mathematics Support Center (QMaSC) can be viewed as a learning community within the larger college or university campus milieu. A literature review prepared for the U.S. Department of Education with the direct aim and title of Strengthening Mathematics Skills at the Postsecondary Level, emphatically states: "The importance of communities in learning cannot be emphasized strongly enough with adult learners" [1]. The writer elaborates, suggesting that adult learners benefit from both interaction with peers and interaction with "knowledgeable others." Outside the college classroom, learning community-centered QMaSCs — typically open to the entire campus community and staffed with mathematically well-trained individuals - provide these beneficial interactive opportunities. Thriving QMaSCs are attractive learning facilities where students from a wide variety of backgrounds can congregate and interact.

Effectively developing a learning community requires outreach and promotion. A QMaSC director can develop and promote awareness of the benefits of QMaSCs within the larger campus community through targeted publicity and outreach. Outreach and promotion will, of course, be wasted effort unless the QMaSC is staffed by individuals truly devoted to assisting students. Thus, the paramount goal of anyone responsible for a QMaSC is to foster and promote a welcoming, threat-free learning community.

Suggested Citation: Laurie Wern Overmann (2016), "Outreach and Promotion", http://dx.doi.org/10.5038/ 9780977674435.ch9 in G. Coulombe, M. O'Neill, M. Schuckers (Eds.) A Handbook for Directors of Quantitative and Mathematical Support Centers, Neck Quill Press, http://scholarcommons.usf.edu/qmasc_handbook.

This material is based upon work supported, in part, by the National Science Foundation under Grant DUE1255945. Any opinions, findings, and conclusions or recommendations expressed in this material are those of the author(s) and do not necessarily reflect the views of the National Science Foundation 
Community outreach has two components: providing service to diverse populations and raising awareness of existing services. Providing excellent service to the student population has the reciprocal benefit of raising awareness of existing services. Increasing awareness of existing services can result in a thriving, vibrant QMaSC learning community. This chapter suggests ways of developing a learning community through outreach and promotion to a diverse campus community. Effective, continual outreach will bring in reluctant students, and the vibrancy of the QMaSC learning community will keep learners returning.

\section{Types of Consumers}

Experience indicates that a QMaSC caters to broadly two types of consumers. One type uses a QMaSC as a place to congregate and interact with like-minded peers. This student group tends to be mathematically inclined, comprised of majors in mathematics, mathematics education, or other STEM fields. The second type of QMaSC consumer seeks academic support from mathematically knowledgeable others. Both groups benefit from the interaction opportunities provided by a QMaSC. Mathematically proficient students often come to "hang out," benefitting from interaction with like-minded peers; outreach to this group of students is minimal, for they will come despite promotional efforts. The less mathematically inclined student consumers seek interactions with hired support staff or with their more mathematically minded peers. The less mathematically proficient students are the more reluctant consumers, requiring QMaSC promotion by the director, faculty, staff, or student peers.

To attract QMaSC consumers, a director engaged in community outreach works long term in ever-widening circles, creating an across-campus network of faculty and staff to identify and direct students to a QMaSC. Over time, a director can contact and communicate across campus with individuals who have direct or indirect access to students in need of mathematics assistance. Directors must interact not only with mathematics faculty, but with faculty and staff in academic support, freshman experience, minority student affairs, disability service offices, and administration; in short, any institutional faculty and staff members who interact with students. Creating a network of individuals across campus to funnel students to a QMaSC is a strategic role of the director.

\section{Promotion in the Innermost Circle}

Research by Solomon, et al. suggests mathematics faculty are effective at reaching mathematically inclined students seeking a place to congregate with like-minded individuals [2]. Interestingly, their research indicated that too many mathematics majors flounder in their first year and change majors, not due to lack of mathematics preparation, but because of a lack of support and inter- 
action with mathematically like-minded peers. Their article claims that the "colonization of [a] mathematics learning space" by mathematically inclined students can be a major determinant in these students' continuing study in mathematics. QMaSCs provide a place to congregate and collaborate with like-minded mathematically inclined individuals, facilitating students' mathematical maturation and consequently continued interest in mathematical studies. For a QMaSC director, this student cohort is a desirable and easy-to-access part of a thriving QMaSC learning community. They not only enjoy and benefit from the camaraderie of mathematically like-minded students but also often act as tutors to their less mathematically capable peers.

The challenge, then, for a QMaSC director is identifying and reaching the less mathematically inclined and typically more reluctant students. A QMaSC director's outreach begins by enlisting the aid of mathematics faculty and institution staff that have direct access to mathematically needful students. To this end, a QMaSC director must establish and maintain an ongoing positive relationship with the institution's faculty, advisors, and staff. Frequent face-to-face interaction and conversation with these colleagues will build relationships. These relationships are maintained through follow-up e-mails or newsletters that provide information about QMaSC services and events.

Directors can enlist the aid of mathematics faculty and university staff in advertising the QMaSC by e-mailing a template announcement or link that includes center hours and policies that can be copied and pasted for inclusion in a syllabus or course management system (e.g. Moodle or Blackboard) site. The advertisement can include pictures of the center or maps to the location so that an interested student gets a "feel for the center," perhaps reducing perceived barriers for coming to the center. Providing faculty and staff with colorful, inviting classroom posters or small hand flyers with the QMaSC schedule and policies to be distributed to students is also helpful.

Provided faculty are willing to give up a few minutes of class time, some QMaSC directors and staff make classroom visits early in the term or at other strategic times in the term (before or immediately following exams) in a direct appeal to the hesitant student. Perhaps outside the classroom milieu, a QMaSC staff member armed with an inviting attitude and a colorful handbill can tempt a student to seek tutoring services when a classroom professor cannot. In larger departments with many classes, directors can and should bring tutorial student staff along on classroom visits to model an inviting attitude before the student staff member undertakes classroom visits "solo." Student-staff tutor presentations can be especially effective because some students receive information more readily from peers.

Directors can send reminders to faculty at key moments of the semester to promote QMaSC services when mathematically needful students are reluctant to seek help. Key moments include those times when semester progress reports are sent out or exams occur. Although faculty can target students - for example those who receive D's or F's on the first exam - all students, even those who might want to improve grades from B to A, benefit from the reminder of QMaSC 
services. Directors can encourage faculty to advertise the QMaSC by providing faculty a template e-mail to send to students.

Sometimes mathematics faculty members spend one or more office hours in the QMaSC. Over time, faculty time spent in a QMaSC can be a very effective means of directing mathematically needful students to a QMaSC. Anecdotal experience indicates that some students view the QMaSC as a more comfortable and less threatening atmosphere than a private office and may be more likely to seek out their mathematics professors in a QMaSC.

Once mathematics department outreach is underway or established, a director of a QMaSC can engage in further promotion through networking with offices across campus.

\section{Promotion in Widening Campus Circles}

Although the name of the office may differ, many campuses have a broadly based academic support office. Such an office provides academic support services to any requesting student, including traditionally underrepresented groups, minorities, students with disabilities, and first generation college students. Oftentimes, one of the functions of this office is to give academic counseling or grant access to a subsidized one-on-one tutor to any requesting student. One goal of the one-onone tutoring is to help a student become a more independent learner. To this end, some academic support offices require a designated number of times for lab attendance before individual tutors are assigned. Communicating and sharing resources with these academic counseling and support individuals serves as another means of outreach, directing mathematically needful students to the QMaSC.

Academic support offices often also give group counseling by way of campus presentations on topics of general interest. As another means of campus community outreach, directors can make presentations on such topics as mathematics study skills or mathematics anxiety. These sessions are often well attended, especially when scheduled strategically. A session on mathematics study skills can serve to help struggling mathematics students to understand the importance of preparation and persistent study in overcoming mathematics anxiety and succeeding in a quantitative course. The goal of such a session is to assist students in becoming independent learners, directing them to the campus QMaSC for mathematics content help. A director can collaborate with mathematics faculty to provide well-timed math anxiety and study skill sessions, an excellent means of outreach to students in need of QMaSC services.

At many institutions, something akin to a "learning fair" is held to highlight the many campus resources available to students. Having a booth that has colorful inviting posters or distributing small hand flyers with the QMaSC schedule is an effective means by which to initiate contact with students. Working in a booth at this fair will also serve to alert and inform a QMaSC director about the needs of diverse student populations. For instance, although a campus is deemed handicap 
accessible, students with mobility issues are more likely to use a QMaSC when equipped with information to help them navigate access to the building and room in which the QMaSC is housed, e.g., on which side of the building the ramp and door are located, where the elevator is located with respect to the QMaSC, etc.

Many campuses also have an office of first-year experience, perhaps with a different name, which serves as an outreach and information clearinghouse for the newest and most naïve students. A first-year experience office and staff can be very effective at advertising the existence of a QMaSC.

Freshman seminar-style courses are quite common at institutions across the country and are usually coordinated by a first-year experience office. Such courses are designed to guide and support students through their first, sometimes daunting, semester, to disseminate correct or dispel incorrect information about the institution, and to direct the most vulnerable students to offices and campus resources. Designed to help students develop communication and critical thinking skills in a non-threatening atmosphere, these courses can be intensely student discussion- and activitybased, serving to develop camaraderie among the group. Further, these courses are often taught by experienced faculty, who are familiar with campus offices, resources, personnel, and most importantly are sympathetic to the plight of first year students. QMaSC directors can use these freshman seminar courses as a means of outreach to students and an opportunity to network with seasoned faculty. Because these courses are typically not driven purely by academic content, professors are often willing to allow QMaSC staff, again at strategic times in the semester, to "pitch" their programs. Connection with the freshman experience office and a network opportunity with like-minded colleagues provide another avenue of outreach and promotion.

Notwithstanding the Family Education Right to Privacy Act of 1970 (FERPA), anecdotal evidence indicates that, for better or for worse, parents are directly contacting mathematics faculty more and more often about a young adult child's progress in a mathematics course [3]. According to FERPA, before an employee of education institution can discuss a student's status with anyone apart from the student, that student must sign a waiver granting an institution representative permission to discuss the student's status or progress with a given individual, typically a well-intentioned parent. Proactively addressing the increase in mathematics faculty and parent interactions, a QMaSC director can schedule a presentation to both students and parents at first year student and parent orientation programs held before the onslaught of fall semester. New student orientation sessions can provide another means of directing students and alerting parents to academic assistance available in a QMaSC before the semester gets underway. Especially refreshing to first year student parents at this time is learning that QMaSC services are offered free of cost.

Academic advisors across campus generally need to be apprised of the location, schedule, and policies of a QMaSC. Inviting these stakeholders to meet periodically is an effective means of promoting an institution's QMaSC. Currently many institutions nationwide are undertaking course redesign in lower-division first-year mathematics courses. At the time of redesign, often campus 
academic advisors need information not only about course placement, but also about the policies of a redesigned course to better advise students. A QMaSC director meeting and interacting with academic advisors at this juncture provides answers to advisors' multitude of questions about courses and the QMaSC's mission. Inviting advisors to the campus QMaSC familiarizes advisors with the physical location, mission, and policies of this campus asset. If a face-to-face meeting with advisors is not feasible, sending an email or newsletter with schedules, resources, links to policies or procedures, template emails for advisors to send to struggling advisees, and a color picture of the center can help make this connection.

Finally, at times when campuses nationwide are faced with budget constraints, a director will eventually be required to promote the existence of a QMaSC to a campus administration or budget review committee, likely requiring data to justify funding for a QMaSC. Thus, QMaSC directors are advised to maintain records over time of student usage patterns. Data collection usually comprises some subset of the following: student user name, ID number, course, instructor, date, time in/out, and QMaSC staff contact. Information may be collected via paper/pencil, swiping a student ID card, or electronic sign-in. In addition to usage data, a director may wish to collect attitudinal data through surveys or a complaint/compliment box, again either traditionally or electronically. In addition to promotion efforts, student usage data can be used to improve QMaSC customer service and satisfaction.

\section{Promotion and Outreach in Even Wider Circles: Traditional and On-line}

Networking with staff and colleagues across campus is perhaps the single most important way to attract and funnel students to a QMaSC. However, distributing newsletters, posters or handbills and an on-line presence provide an efficient means for students to access scheduling information. Key to effective newsletters, posters, handbills, or websites, is an economy of, but welcoming, language, and a schedule of hours. Enlisting the aid of an on-campus graphic design student or group in need of a project can result in an attractive, inviting poster, newsletter, handbill, or website.

Many post-secondary institutions' QMaSCs have an on-line presence as evidenced by a quick Google search of "Mathematics Tutoring Lab." All on-line websites for QMaSCs include hours of operation; some websites include names of tutors often with their particular mathematics expertise (statistics, differential equations, etc.). Several websites include information about group tutoring sessions or mini-lectures, access to on-line mathematics practice software, and links to old exams. Some websites have an on-line application for a student to schedule an appointment directly with a lab tutor. Some have information about private tutors and their fees in addition to the free-of-charge 
QMaSC. Some websites include links to other familiar mathematical websites (The Mathematics Forum with Ask Dr. Math, Cut-the-Knot.org, The History of Mathematics, and others).

Less common among these websites, but worth the consideration of QMaSC director implementing an online presence, is the promotion of responsible learning. Naïve students desperate for mathematics help too often arrive at QMaSCs with unrealistic goals, leading to frustration for themselves and their tutors. Proactive directors promoting QMaSC services should include a list of what to expect and tips for a successful tutoring session which can serve to assist in the academic maturation of the learner. To address some common issues, more than one website includes a warning about how busy a lab can be, suggesting that students "plan for success" and manage study time leading up to an exam. All websites should offer tips about a successful tutoring session, including reminders to a prospective tutee to bring both learning tools (book, notes, paper, writing implement) and to come with specific questions. All of these tips can also be made available in hard copy within the QMaSC.

A cursory tour of various websites yields some singular suggestions for a QMaSC director contemplating an online presence. One website has a YouTube video of a walk-through tour of the lab. The short tour includes the physical space in addition to some short out-takes of oneon-one tutor student conversation and groups of students working together. This is a thoughtful, welcoming gesture, providing viewer a virtual glimpse of what to expect at a lab without raising anxiety by requiring any commitment on the part of a curious student. Another QMaSC offers Skype conferencing with tutors.

\section{$6 \quad$ Full Circle}

The paramount goal of a QMaSC director is to foster and promote a welcoming, threat-free learning community. A quality learning experience includes the provision of a learning space and of resources within that space that facilitate student and peer interaction. Such a thriving learning community is developed over time through tireless outreach, networking, and promotion.

\section{Bibliography}

[1] U.S. Department of Education, Office of Vocational and Adult Education, "Strengthening mathematics skills at the postsecondary level: Literature review and analysis." www.eric.ed.gov, 2005 .

[2] Y. Solomon, T. Croft, and D. Lawson, "Safety in numbers: Mathematics support centres and their derivatives as social learning spaces," Studies in Higher Education, vol. 35, no. 4, pp. 421$431,2010$. 
[3] U.S. Department of Education, Family Policy Compliance Office, "Family Educational Rights and Privacy Act (FERPA)." http://www.ed.gov/policy/gen/guid/fpco/ferpa/ index.html, 2013. 